\title{
Distribution of Characteristic Ways That Students Think about the Future in Large Enrollment Engineering Classes
}

\section{Miss Catherine McGough, Clemson University}

Catherine McGough is currently a graduate research assistant in Engineering and Science Education at Clemson University. She obtained her B.S. in Electrical Engineering from Clemson University in 2014. Her research interests are in undergraduate engineering student motivations and undergraduate engineering problem solving skill development and strategies.

\section{Dr. Lisa Benson, Clemson University}

Lisa Benson is a Professor of Engineering and Science Education at Clemson University, with a joint appointment in Bioengineering. Her research focuses on the interactions between student motivation and their learning experiences. Her projects involve the study of student perceptions, beliefs and attitudes towards becoming engineers and scientists, and their problem solving processes. Other projects in the Benson group include effects of student-centered active learning, self-regulated learning, and incorporating engineering into secondary science and mathematics classrooms. Her education includes a B.S. in Bioengineering from the University of Vermont, and M.S. and Ph.D. in Bioengineering from Clemson University. 


\section{Distribution of Characteristic Ways That Students Think about the Future in Large Enrollment Engineering Classes}

\section{Introduction}

Motivation is the underlying reason why students behave in a certain way; therefore, when trying to influence student behavior related to learning and developing study skills, instructors and researchers must understand students' motivations in order to appeal to those motivations. The purpose of this study is to describe the motivation of undergraduate engineering students in large enrollment classes in terms of their perceptions about the future.

This paper presents the first half of the quantitative strand of a larger sequential exploratory mixed methods design ${ }^{1}$. The purpose of the mixed methods study is to describe the relationship between students' future time perspectives (FTPs) and their problem-solving behaviors. To discuss the relationship between FTP and problem solving behaviors, first student's FTPs must be understood. Therefore, the purpose of the quantitative stand of the mixed methods study is to describe undergraduate engineering students' FTPs. The research question addressed in this study is: What is the distribution of characteristic FTP types among undergraduate engineering students in large enrollment classes?

\section{Background}

Engineering Students' Perceptions of the Future

All students are motivated to varying degrees by their future goals ${ }^{4-7}$; these future goals, how they are integrated into the present, and how they affect actions in the present are a student's future time perspective (FTP $)^{8}$. FTP is a construct within the theory of psychological time along with time orientation, or the preference of thinking in the past, present, or future, and time attitude, or how positive or negative one thinks about time ${ }^{6}$. Education is future oriented ${ }^{6,8}$; therefore, when discussing engineering students' psychological time, the focus is on the future time orientation as it relates to FTP. Research has identified several constructs within FTP: valence, extension, future time attitude, perceived instrumentality, density, and connectedness $^{5-12}$.

\section{Constructs of Future Time Perspectives (FTP)}

Valence in psychology literature refers to how attractive or aversive a phenomenon is. In FTP literature valence is used to describe the value that an individual perceives thinking about the future or setting future goals to be ${ }^{11}$.

Extension refers to how far into the future a person is setting goals. One's extension can be short, where only the very near future is considered; or extension can be long, where psychological time extends into the distant future ${ }^{5,6}$. Future time attitude is one's time attitude directed towards the future; one's future time attitude can be positive or negative ${ }^{13}$. Perceived instrumentality is how useful the person perceives a certain task to be in regards to their future goals. Perceived instrumentality is a cognitive aspect of FTP, and is described as a more task specific dimension ${ }^{6}$. The task can be related to the future goal as a step that is needed to reach a long term goal ${ }^{8,12,14}$; 
this is exogenous instrumentality ${ }^{6,12}$. An example of exogenous instrumentality would be when a student believes they need to pass a course in order to reach their academic goals ${ }^{8}$. The task can be perceived as directly related to the future goal, which is described as endogenous instrumentality ${ }^{6,12}$. An example of endogenous instrumentality is a student believing that they need the information from a course in order to be successful in their future career ${ }^{8}$.

These three dimensions - extension, future time attitude, and perceived instrumentality — can be represented as three axes, as demonstrated in Figure $1^{15}$. On these axes one's FTP can be represented as different shapes of a cone ${ }^{10,16}$. Within these cone shapes, other aspects of FTP are represented: density and the effect of the future on the present. Density refers to the number of future goals one has in the future, represented by the sharpness of the cone shape ${ }^{6,13}$. The effect of the future on the present is how one perceives their actions in the present, such as choosing a major or taking a specific class, as influenced by their personal future goals. Effect of future on present is a form of connectedness, the tendency to cognitively connect the present and the future ${ }^{6,8}$.

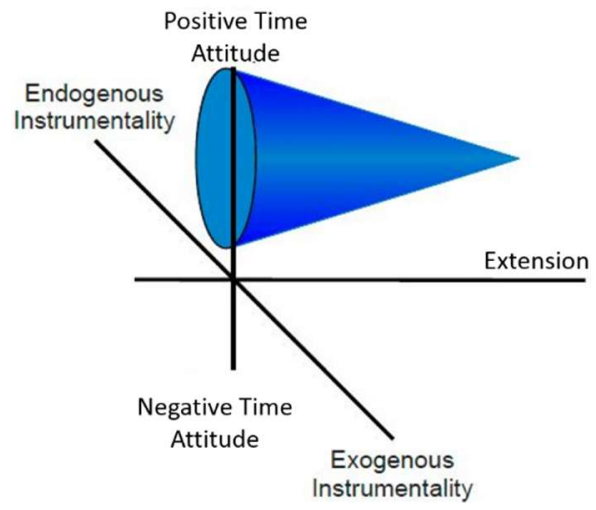

Figure 1: An individual's FTP can be represented as a cone shape on three axes: Perceived Instrumentality, Future Time Attitude, and Extension ${ }^{15}$.

Also situated within FTP literature is the idea of an individual's future possible selves, which is one's ideas of who they can become (realistic), who they want to become (ideal), and who they do not want to become (avoided) in the future ${ }^{6,16-18}$. These future possible selves serve as incentives or motivations for a student's behaviors in the present ${ }^{17}$. A person whose ideal and realistic future possible selves do not match may have a more negative future time attitude ${ }^{7}$.

\section{Qualitative Work Identifying Three Characteristic FTP Types}

Our research group conducted a phenomenographic study, in which we identified three characteristic ways that engineering students perceive their future. Students in biomedical (BME) and mechanical (ME) engineering majors $(\mathrm{N}=18)$ were selected based on their responses to a quantitative survey focusing on FTP. Students who volunteered to participate in interviews were selected for maximum variation in their FTP attributes. Researchers interviewed the participants, focusing on the participants' future goals, specifically their career goals, their different possible selves, and their perception of how future and present connect (or do not connect). 
The results of the study showed three distinct characteristic FTP types, shown in Figure 2. Each of the FTP types fall on the axes described in the background, and are visualized as three differently shaped cones. First, the Cake cone has a short extension, with a high density of different future goals, and does not connect how the future is affecting the present. Second, the Sugar cone has a long extension, with a lower density, resulting in one distinct long-term goal, and these students perceive how the future effects their present actions. Third, the Waffle cone has an extension between Sugar and Cake, and connects the future and the present. However, Waffle has a more negative future time attitude; their ideal and realistic future possible selves are conflicting, resulting in a more negative outlook for their future. These results have also been replicated in a quantitative study using a survey described in the next section ${ }^{19}$.

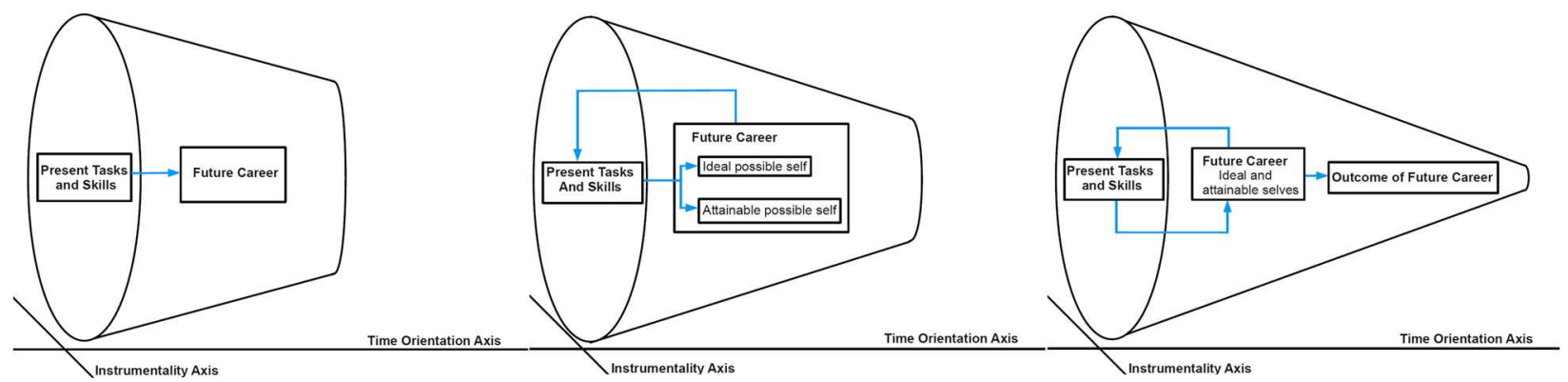

Figure 2: Cake (left) has a shorter and wider cone, representative of their shorter extension into the future; Sugar (right) has high density and extension — one goal deep into the future — represented by the long and narrow cone; and Waffle (middle) has a medium clarity compared to the Cake and Sugar ${ }^{16}$.

\section{$\underline{\text { Survey Development and Validation for FTP }}$}

In previous work, our group used a validated survey instrument measuring students' motivations and attitudes in engineering, the MAE survey, to quantitatively measure different subscales of motivations and attitudes, include a subscale of the FTP, of various majors and years of undergraduate engineering students. Cluster analyses of survey data has consistently resulted in three distinct characteristic FTP types ${ }^{7,19-21}$. Based on the results of the phenomenographic study described above, our research identified the characteristics of the three FTP types that would help quantitatively distinguish between the three of them. We then developed additional items related to those characteristics to include in the MAE survey, to facilitate quantitatively identifying students into one of these three characteristic FTP types. We tested these items in two pilot studies for validity and reliability; the result of the tests was an updated FTP subscale of the MAE survey which measured seven factors of FTP ${ }^{7}$. These seven factors, as shown in Table 1, consist of constructs that emerged from FTP literature and our qualitative analyses.

\section{Constructs Measured in the FTP Subscale of the MAE Survey}

Effect of the Future on the Present (FoP), Exogenous Perceived Instrumentality (PIEX), and Endogenous Perceived Instrumentality (PIEN) all follow the definitions described in the "Constructs of FTP" section. These three factors are all context dependent, in that the survey items for these factors refer to the specific context of an engineering course the students are currently in (i.e. "I will use the information I learn in this course in the future.") 
Attitude Towards the Future (Attitude) is similar to the FTP construct of future time attitude described earlier, with the added consideration of future possible selves; students with a high time attitude believe that they will be able to achieve their ideal possible future career, while students with a low time attitude believe that their realistic future possible career is different from ideal. Clarity indicates how well-defined students' goals deep into the future are. Clarity is similar to both the construct of extension and density; a student with high clarity will have one well-defined goal deep into the future. Value is similar to valence; value of the Future (Value) measures how important students perceive thinking about their future career goals to be. Lastly, Perceptions of their Future in Engineering (Future) is how certain the student is about having a future career in engineering. The items for these four factors (Attitude, Clarity, Value, and Future) do not depend on a specific context, such as the course that the student is in when taking the survey.

\begin{tabular}{|c|l|l|}
\hline \multicolumn{2}{|c|}{ Table 1: Constructs of The Students' Future Goals Measured on the Survey } \\
\hline $\begin{array}{c}\text { Nority of Future } \\
\text { Goals }\end{array}$ & Clarity & $\begin{array}{l}\text { The student has a well-defined future goal, deep into the future. } \\
\text { "I have a clear idea of what my first job after graduation will be." }\end{array}$ \\
\hline $\begin{array}{c}\text { Value of the Future } \\
\text { Perceptions of the }\end{array}$ & Value & $\begin{array}{l}\text { The student believes that thinking about their future career goal is } \\
\text { important. } \\
\text { "My future career is too far off to consider now." }\end{array}$ \\
\hline $\begin{array}{c}\text { Future in Engineering } \\
\text { Attitude Towards the } \\
\text { Future }\end{array}$ & Future & $\begin{array}{l}\text { The student is certain about being an engineer. } \\
\text { "Engineering is the most rewarding future career I can imagine for } \\
\text { myself." }\end{array}$ \\
\hline \multicolumn{2}{|c|}{$\begin{array}{l}\text { The student believes they can achieve their ideal possible future } \\
\text { career. } \\
\text { "I believe I can obtain the career I want." }\end{array}$} \\
$\begin{array}{c}\text { Effect of the Future } \\
\text { on the Present }\end{array}$ & FoP & $\begin{array}{l}\text { The student believes their future goals affect what they do in the } \\
\text { present. } \\
\text { "My future career influences what I want to learn in this course." }\end{array}$ \\
\hline $\begin{array}{c}\text { Exogenous Perceived } \\
\text { Instrumentality }\end{array}$ & PIEX & $\begin{array}{l}\text { The student finds their class grade to be useful for their future } \\
\text { career. } \\
\text { "I must pass this course in order to reach my academic goals." }\end{array}$ \\
\hline $\begin{array}{c}\text { Endogenous } \\
\text { Perceived } \\
\text { Instrumentality }\end{array}$ & PIEN & $\begin{array}{l}\text { The student finds their learning in class useful for their future } \\
\text { career. } \\
\text { "I will use the information I learn in this course in the future." }\end{array}$ \\
\hline
\end{tabular}

\section{Methods}

In order to answer the research question, the distribution of characteristic FTP types among undergraduate engineering students in large enrollment classes was determined by implementing a survey instrument designed to measure FTP, conducting a k-means cluster analysis to identify the characteristic FTP types, and using descriptive statistics to describe the distribution of 
characteristic FTP types across all students, by university, by class, by major, and by gender identity.

\section{$\underline{\text { Participant Selection }}$}

Participants were recruited through their instructors by targeting instructors at universities who have large-enrollment engineering classes. A Large-enrollment class is defined here as a class with a greater than 50:1 student to instructor ratio. Universities which were the most likely to have large-enrollment classes were identified using statistics on the number of engineering bachelor's degrees awarded ${ }^{22}$ and percentage of classes with 50-99 students, using data from the Princeton Review and collegedata.com.

Instructors at those universities as well as instructors at large engineering institutions who, through networking, indicated an interest in the study were contacted. These instructors were sent emails asking them to distribute the survey to their class in return for descriptive statistics of their own students' motivation attributes, along with a summary and a short explanation of results.

In this part of the quantitative strand, seven instructors at four universities indicated willingness to distribute the survey to a total of eight classes ( $\mathrm{N}=1040$ possible participants). The Institutional Review Boards (IRB) at each university were then contacted for permission to distribute the survey. The instructors were provided with a description of the study to share with their students during class and an email with the electronic survey link to forward to their students. The instructors were asked to forward the email, introduce the study in class, and, if possible for their class, offer extra incentives.

\section{Survey Instrument}

The survey used in this study consists of demographic questions (race, gender, year, major, sexual orientation, highest level of parent education, parents' background) ${ }^{23}$, contact information (name and email), and 30 items which measure 7 FTP factors, a subscale of the MAE survey described in the background. The FTP subscale is measured on a 7-point anchored scale, where a score of 1 indicates "strongly disagree" and a score of 7 indicates "strongly agree." The definition of the factors and an example item for each factor is provided in Table 1. An electronic version of the survey was used in order to comply with the IRB of participating institutions. By distributing an electronic survey, the participating instructors are not engaged in the research; they did not have access to the raw data at any point in the study. The instructors received composite results for their class in the form of a five page summary provided by the researchers, with all identifying information of the students removed.

\section{Reliability Testing for Survey Instrument}

The survey instrument has been developed and tested for reliability and validity, as described in the background, for Mechanical (ME), Biomedical (BME), Electrical (EE), Computer (CpE), Industrial (IE), and first year engineering students at a southeastern and a northwestern land grant research institutions ${ }^{7,19-21}$. To determine that the survey is reliable for the sample in this study, an exploratory factor analysis (EFA) was performed on part of the data, using a maximum 
likelihood factor analysis and promax rotation. A promax rotation is appropriate for this data since it allows for correlation between constructs ${ }^{24}$, which theory dictates is true for the FTP constructs being measured in this survey. Using a maximum likelihood factor analysis, how well the items load onto the theorized constructs was tested, with the assumption that multivariate normality is not severely violated by the data ${ }^{24,25}$. To ensure that this assumption is accurate, the researchers checked that the skew and kurtosis were within acceptable ranges $(>|2.0|$ and $>7.0$, respectively).

To determine the number of factors in the instrument to extract in the EFA, a scree plot was used. The elbow, or the point at which the slope significantly decreases, indicates the number of factors to include in the EFA. The maximum likelihood factor analysis, was used to determine the factor loadings of each item; items with acceptable loadings (loadings $>0.4$ ) were included in the data analysis. A confirmatory factor analysis (CFA) was then performed on the rest of the data. Cronbach's alpha was used to test the internal consistency reliability of the factors ${ }^{26}$.

\section{Analysis of Survey Data}

Two weeks after the instructors had distributed the surveys, the survey data collection was closed and the researchers proceeded with the data analysis. The data was cleaned by removing any student not consenting to participation in the study, assigning each participant a study ID, and removing all identifying information.

A k-means cluster analysis was used to group the participants into characteristic FTP types. Kmeans cluster analysis is appropriate for large sample sizes where the number of clusters $(\mathrm{k}=3)$ is hypothesized based on theory or previous studies, so it is the appropriate clustering method for this study ${ }^{27,28}$. Based on prior work, there were anticipated clusters and factor means. However, the prior work was not a multi-institutional study, so it was reasonable to believe that there may be some differences in the results in this data. For this reason, other values for $\mathrm{k}$ were considered; a within-cluster sum-of-squares plot was used to determine what value of $\mathrm{k}$ to use.

Since data was collected from multiple classes at multiple universities, only the non-context dependent factors (Attitude, Clarity, Value, and Future) were used to cluster the students. The context dependent factors (FoP, PIEN and PIEX) we would expect to vary greatly by class, since the items for these factors refer to the course for which the students are completing the survey (i.e. "this course"). The factor means of each of the factors was included in the description of the clusters. Descriptive statistics, percentages, were used to describe the distribution of characteristic FTP types across each institution, certain majors, and certain demographics.

A summary was provided to the participating instructors with the results for their course. The distribution of the clusters in their class, demographics of the class, and an explanation of these results were provided to the instructors. Context dependent factors were included in the summary for the instructors.

\section{Results and Discussion}

Description of Participants 
The total number of participants included in the study was $\mathrm{N}=416$, after removing participants who did not consent to participate in the study, were under the age of 18, or did not fill in an appropriate course (i.e. "grade"). The context dependent survey items refer to "this course;" therefore, students were asked to specify the course that they were thinking of while filling out the survey: "What course are you completing this survey for?" Their entry was used to fill in the prompt for the following questions: "The following questions relate to your attitudes and beliefs about your experiences in [course] and in [major]. Please rate your agreement for each item on a scale from 'Strongly Disagree' to 'Strongly Agree'." Therefore, if a student did not enter an appropriate course, their responses were considered invalid.

The participants were from three different universities: a large (about 20,000 students) southwestern land grant research institution (SW Institution), a large (about 40,000 students) midwestern land grant research institution (MW Institution), and a smaller (about 10,000 students) southeastern land grant institution (SE Institution). These institutions will be referred to by their location throughout the rest of the paper, to maintain confidentiality of the results. The distribution method varied according to the IRB restrictions at each institution; instructors at some institutions were able to introduce the study in class and provide an incentive for completing the survey, while other instructors were only able to forward the email with the survey link. The distribution method drastically altered the response rate for these classes. A description of the courses, number of students, and distribution method used at each of these institutions is provided in Table 2 .

Sophomore engineering courses were targeted, but students ranged in the number of years they had been in their discipline. The Introduction to Computer Programming at the SW Institution had $\mathrm{N}=198$ first year students respond to the survey. At this university students start their engineering discipline in their first year, rather than start in a common first year program as at many other institutions; therefore, first year students had the option to take the Introduction to Computer Programming course. First year $(\mathrm{N}=198)$ and sophomore $(\mathrm{N}=152)$ students comprised most of the participants, but there were also juniors $(\mathrm{N}=45)$ and seniors $(\mathrm{N}=11)$ who responded to this survey.

\begin{tabular}{|c|c|c|c|c|}
\hline \multicolumn{5}{|c|}{ Table 2: Description of Participants, Their Courses, and The Distribution Method for the Survey in } \\
Each Course \\
\hline University & Course Name & $\begin{array}{c}\text { Number of } \\
\text { Students } \\
\text { Enrolled }\end{array}$ & $\begin{array}{c}\text { Number of } \\
\text { Participants }\end{array}$ & Distribution Method \\
\hline $\begin{array}{c}\text { SW } \\
\text { Institute }\end{array}$ & $\begin{array}{c}\text { Introduction to } \\
\text { Computer } \\
\text { Programming }\end{array}$ & 500 & 284 & $\begin{array}{c}\text { Announced in class } \\
\text { Forwarded email with link in lab } \\
\text { Received class credit for completion }\end{array}$ \\
\hline $\begin{array}{c}\text { MW } \\
\text { Institute }\end{array}$ & $\begin{array}{c}\text { Fundamentals of } \\
\text { Environmental } \\
\text { Engineering }\end{array}$ & 150 & 14 & Forwarded email with link outside of \\
class \\
\hline $\begin{array}{c}\text { SE } \\
\text { Institute }\end{array}$ & $\begin{array}{c}\text { Introduction to } \\
\text { Microprocessors }\end{array}$ & 58 & 54 & $\begin{array}{c}\text { Announced in class } \\
\text { Received class credit for completion }\end{array}$ \\
\hline
\end{tabular}




\begin{tabular}{|c|c|c|c|c|}
\hline $\begin{array}{c}\text { SE } \\
\text { Institute }\end{array}$ & $\begin{array}{l}\text { Engineering } \\
\text { Materials } \\
\text { (Instructor 1) }\end{array}$ & 82 & \multirow{2}{*}{64} & \multirow{2}{*}{$\begin{array}{l}\text { Announced in class } \\
\text { Forwarded email with link outside of } \\
\text { class } \\
\text { Received class credit for completion }\end{array}$} \\
\hline $\begin{array}{c}\text { SE } \\
\text { Institute }\end{array}$ & $\begin{array}{l}\text { Engineering } \\
\text { Materials } \\
\text { (Instructor 2) }\end{array}$ & 90 & & \\
\hline
\end{tabular}

Students indicated a gender identity of either "male," "female," "male" and "cisgender," or "female" and "cisgender." No students identified as "agender" or "genderqueer." A majority of students, $73 \%$, identified as male or male and cisgender, compared to the national average of $81 \%$ male 22 . A majority of students, $70 \%$, identified as white, compared to the national average of $66 \%$. National data on the sexual orientation of engineering students is lacking, as it is often not included in demographic questions unless directly related to the research question of the study; however, it is a relevant demographic variable important for understanding the experiences of non-heterosexual engineering students ${ }^{23}$. In this study students were asked to describe their sexual identity. A vast majority of students identified as heterosexual $(\mathrm{N}=405$, 97\%); some students identified as homosexual $(\mathrm{N}=3)$, bisexual $(\mathrm{N}=5)$ and asexual $(\mathrm{N}=2)$.

\section{Validity and Reliability Testing}

The validity and reliability testing resulted in the removal of several items from the analysis. All items had acceptable skew and kurtosis for the assumption of normality, |skewness $\mid<1.4$ and kurtosis $<4.6$, except for one item, which was removed.

Next, the exploratory factor analysis (EFA) was run on the SW Institution data. This data was used for the EFA, because it was the largest data set, and classes at the SW Institution started two weeks earlier than the other institutions, thus it was the first data set received. The scree plot indicated either five or six factors. Since the survey was intended to measure seven factors, an EFA was run for seven factors first. The results of the EFA with seven factors was consistent with previous results and literature, so the analysis moved forward with seven factors. Five items did not load into any factors, and were removed from the analysis. These items did not have strong loadings in the preliminary survey analysis, and the other items loaded as expected. Since the EFA had results similar to previous implementations, a CFA was used for the rest of the data.

Cronbach's alphas for Attitude, Clarity, Value, Future, and PIEN were all above 0.8. The alphas for FoP and PIEX were 0.71 and 0.63 respectively. All alphas were above the acceptable value of 0.7 except for PIEX. PIEX was still reported, but it is noted that the internal consistency reliability for this factor is low.

\section{Description of Characteristic FTP Types}

The groups of characteristic FTP types were identified using a k-means cluster analysis. The within-cluster sum-of-squares plots indicated 2-4 clusters. In the k-means analysis, two, three, and four clusters were examined. $\mathrm{K}=3$ clusters accounted for the most variance in the data $(60 \%)$, and had factor means consistent with previous qualitative and quantitative results. The factor means for each of the FTP types is shown in Table 3. 
The means of the non-context dependent factors for each cluster are consistent with the three groups described in prior work (Cake, Sugar, and Waffle cones). The Cake group has less welldefined future career goals that only extended into the near future, as demonstrated by their Clarity mean score (2.9 out of 7). The Clarity mean scores for Sugar (5.1 out of 7) and Waffle (4.7 out of 7) groups have more well-defined future career goals extending into the future. All three of the groups had a mean greater than 3.5 for the Attitude score, but the mean Attitude score for Waffle (3.8 out of 7) is lower than either Sugar (5.8 out of 7) or Cake (4.8 out of 7). These mean scores indicate that the Waffle group has a more negative outlook on their future than Sugar or Cake; they have less of a belief that they will achieve their ideal future career goal. Sugar indicated having a high perception that thinking about their future career is important, with a mean Value score of 6.3 out of 7, which is not surprising since they have more well-defined future goals. The Waffle group had a lower mean Value score (4.5 out of 7), possibly due to their more negative outlook of the future. All students in this study had were fairly certain about their future in engineering, with mean Future scores ranging from 5.1 to 5.5 out of 7 . The mean Future score for Waffle (5.5 out of 7) was the highest.

\begin{tabular}{|c|c|c|c|c|c|c|c|}
\hline \multicolumn{10}{|c|}{$\begin{array}{c}\text { Table 3: Factor means (reported on a scale of 1-7) for FTP types across all students } \\
\text { (N=416) }\end{array}$} \\
\hline $\begin{array}{c}\text { FTP } \\
\text { "Cone” } \\
\text { Type }\end{array}$ & \multicolumn{2}{|c|}{ Non-Context Dependent Factors } & \multicolumn{2}{c|}{ Context Dependent Factors } \\
\cline { 2 - 8 } & Clarity & Attitude & Value & Future & FoP & PIEX & PIEN \\
\hline Cake & 2.9 & 4.8 & 5.9 & 5.1 & 4.7 & 5.0 & 5.2 \\
\hline Sugar & 5.1 & 5.8 & 6.3 & 5.2 & 4.9 & 5.3 & 5.1 \\
\hline Waffle & 4.7 & 3.8 & 4.5 & 5.5 & 4.9 & 5.2 & 5.3 \\
\hline
\end{tabular}

The means for the context dependent factors, FoP, PIEX, and PIEN, do not vary much across the three groups. These scores have more significant implications in terms of individual classrooms, because these factors are context-dependent (asking students about their perceptions in "this course" in which they took the survey). The FoP, PIEX, and PIEN scores helped inform instructors of each course about how students were connecting their future career goals and the material in that course.

A separate k-means cluster analysis was completed for each institution, and results were similar to the cluster analysis run on the combined data set. The means of the factors in each cluster indicate that the Clarity, Attitude, and Value factors are the factors most useful for distinguishing between the three characteristic FTP types, since the scores for Future, FoP, PIEX, and PIEN are similar across all of the groups. The validity and reliability testing of the factors and their items, along with the consistent cluster analysis results at multiple universities indicate that in future studies these three FTP types may be appropriately determined using linear discriminate analysis $^{29}$, and that a cluster analysis is not necessary.

\section{Distribution of Characteristic FTP Types}

After the cluster analysis was used to determine the three characteristic FTP types and to group students into one of the three clusters, descriptive statistics were used to describe the distribution 
of characteristic FTP types across universities, majors, and demographics. The descriptive statistics were calculated using the results of the cluster analysis of the combined data set; these results are shown in Table 4. Across all of the students, the three FTP types were nearly evenly distributed, with Sugar being slightly more dominant. A majority of sophomores $(60 \%)$, the target population for the larger mixed methods study, were in the Sugar group. These students have well-defined future goals deep into the future that they believe they can achieve.

A majority of male students (those who identified as "male" or "male" and "cisgender") fall into the Sugar (37\%) group and Waffle (35\%) group, which has a lower future time attitude (perception that they can realistically achieve their ideal future career goals). There are more non-male students (those who identified as "female" or "female" and "cisgender") who fall into the Cake group (39\%), which has less well-defined future goals in engineering.

Sugar also contains the largest number of students who identified as white (38\%) and heterosexual (37\%). The students who did not identify as heterosexual $(\mathrm{N}=10)$ fell into the following categories: one was in Cake (10\%), four were in Sugar (40\%), and five were in Waffle $(50 \%)$. Among the participants in this study, half of those who identified as homosexual, bisexual, and asexual had a low time attitude towards their future (Attitude scores ranged from 1 to 3.7 out of 7). These students do not believe that they will realistically be able to achieve their future career goals. Although we can observe that the Attitude scores for these five students are lower than even the mean scores of the group with the lowest overall Attitude score (Waffle), it is difficult to conjecture as to why given the limited literature on non-heterosexual students in engineering.

\begin{tabular}{|l|c|c|c|c|c|c|c|c|c|c|}
\hline \multicolumn{1}{|c|}{ Table 4: Results for Characteristic FTP Type Factor Means and Distribution Across All } \\
\hline & All & Soph. & Male & White & $\begin{array}{c}\text { Hetero } \\
- \text {-sexual }\end{array}$ & SE & SW & ME & CE & EE \\
\hline \% Cake & 30 & 44 & 28 & 31 & 30 & 32 & 28 & 27 & 30 & 33 \\
\hline \% Sugar & 37 & 60 & 37 & 38 & 37 & 33 & 39 & 41 & 42 & 30 \\
\hline \% Waffle & 33 & 48 & 35 & 31 & 33 & 35 & 33 & 32 & $\mathbf{2 8}$ & 36 \\
\hline N = & $\mathbf{4 1 6}$ & $\mathbf{1 5 2}$ & $\mathbf{3 0 3}$ & $\mathbf{2 9 0}$ & $\mathbf{4 0 5}$ & $\mathbf{1 1 8}$ & $\mathbf{2 8 4}$ & $\mathbf{1 3 6}$ & $\mathbf{5 0}$ & $\mathbf{3 3}$ \\
\hline
\end{tabular}

The majors of Mechanical (ME) and Civil (CE) Engineering had the highest percentage of students in Sugar (41\% and 42\% respectively). Electrical (EE) Engineering had the lowest percentage of students in Sugar (30\%), and the highest in Waffle (36\%). The distribution of the three FTP types in EE was different not only in comparison with the other majors', but also in comparison to the total population.

\section{Dissemination of Results to Instructors}

The instructors in this study were kept informed about the process of the study throughout. The instructors were given a description of the study and a copy of the survey being distributed prior to participant recruitment. The instructors were kept up to date about the response rate from their course. About two months after the survey closed, the instructors were sent a five-page summary 
of the results from their class. The summary included: overview of results, project summary, definitions of the constructs, descriptions of the three FTP types, distribution of the FTP types in their class, description of the context dependent factor scores, implications tailored to their results, description of demographics, and future work. An example summary is provided in the Appendix.

The description of the context dependent factors is hoped to be especially beneficial to the instructors. These factors will give some insight into what their students hope to get out of the class: if the students are primarily concerned about getting a passing grade (PIEX), or if the students are focused on fully understanding the material (PIEN) perhaps because their future career goals are driving them to understand the material (FoP). For example, since students who see the usefulness or instrumentality of a task have shown increased performance in academic settings ${ }^{30}$, if students in the course have low PIEN, the instructor may want to try to include more examples of applications of the material.

\section{Conclusions and Implications}

The analysis of survey data measuring engineering students' FTP resulted in three groups of students with distinctly different FTP characteristics. These three groups have shown consistently across five different universities and several engineering majors and years, indicating that these three groups are most likely representative of the social reality of engineering student motivation.

These three characteristic FTP types are described as: 1) Sugar, or students' with well-defined ideal future goals deep into the future which they believe they can achieve, 2) Cake, or students' with ill-defined future goals, and 3) Waffle, or students' with ideal future career goals in engineering that they do not believe they will be able to achieve. Participants in this study were nearly evenly distributed across the three types. The distribution of these three groups varied across classes, institutions, majors, and demographics.

Instructors of large enrollment sophomore-level courses can use this information to better understand the motivations of their students. These results will help inform the direction of future studies on motivation. Future work will be needed to explain some of these differences, particularly the low time attitude scores of half of the students who identified as homosexual, bisexual, and asexual.

In addition to the description and distribution of the characteristic FTP types, this paper provides a valuable example of directly disseminating results to instructors. Future work will continue to improve the cycle of results to practice.

\section{Limitations and Future Work}

The consistently appearing three characteristic FTP types indicate that cluster analysis may no longer be the best method for determine how students fit into these groups. In future studies, the three characteristic FTP types will be defined using a weighted equation of the Attitude, Clarity, Value, and Future scores. The equation will be generated using linear discriminant analysis with these preliminary results as the test data. 
The distribution of this survey will be improved in future studies to eliminate some of the issues seen in this paper. In this study, data from only three institutions were collected, and only one of those institutions was in the list of ten target intuitions. A second iteration of this study is currently being implemented to capture data from an additional five of the intuitions. The fill-in-the-blank option in the survey allowed for too much variance in the context dependent factors. In future distributions of this study, a dropdown box will be used containing the course names that the students were contacted in, to eliminate this issue.

At the end of the study, instructors were given the opportunity to provide anonymous feedback about their experiences with the survey distribution and the usefulness of the results they received about their class. No instructor has opted to provide this information to date; however, in future studies, instructors will be asked for feedback as well, in the hopes of improving the usefulness of this survey and survey results for instructors. Future studies will continue to focus on improving the cycle of research to practice.

\section{$\underline{\text { References }}$}

1. Cresswell JW, Clark VLP. Designing and Conducting Mixed Methods Research. second. Sage publications; 2011.

2. National Academy of Engineering. Grand Challenges for Engineering. http://www.engineeringchallenges.org/. Published 2012.

3. National Academy of Engineering. Advance Personalized Learning. NAE Grand Challenges for Engineering.

4. Malka A, Covington M V. Perceiving school performance as instrumental to future goal attainment: Effects on graded performance. Contemp Educ Psychol. 2005;30(1):60-80. doi:10.1016/j.cedpsych.2004.04.001.

5. Lens W, Paixão MP, Herrera D, Grobler A. Future time perspective as a motivational variable: Content and extension of future goals affect the quantity and quality of motivation. Jpn Psychol Res. 2012;54(3):321-333. doi:10.1111/j.1468-5884.2012.00520.x.

6. Husman J, Lens W. The Role of the Future in Student Motivation. Educ Psychol. 1999;34(July 2014):113-125. doi:10.1207/s15326985ep3402.

7. McGough C, Kirn A, Benson L. Work in Progress : Developing a Quantitative Instrument for Measuring Undergraduate Engineering Students ' Future Time Perspectives. In: American Society for Engineering Education. ; 2016.

8. Hilpert J, Husman J, Stump GS, Kim W, Chung WT, Duggan MA. Examining students' future time perspective: Pathways to knowledge building. Jpn Psychol Res. 2012;54(3):229-240. doi:10.1111/j.1468-5884.2012.00525.x.

9. McGough C, Kirn A, Benson L. Relationships between Engineering Students' Future Time Perspectives and Their Problem Solving Processes. NARST Conf. 2015:1-5.

10. McGough C, Faber C, Kirn A, Benson L. Connections between Undergraduate Engineering Students ' Problem Solving Strategies and Perceptions of Engineering Problems. In: ASEE Annual Conference. ; 2015.

11. Husman J, Shell DF. Beliefs and perceptions about the future: A measurement of future time perspective. Learn Individ Differ. 2008;18(2):166-175. doi:10.1016/j.lindif.2007.08.001. 
12. Husman J, Derryberry WP, Crowson HM, Lomax R. Instrumentality, task value, and intrinsic motivation: Making sense of their independent interdependence. Contemp Educ Psychol. 2004;29:63-76. doi:10.1016/S0361-476X(03)00019-5.

13. Daltry MH, Langer P. Development and Evaluation of a Measure of Future Time Perspective. Percept Mot Skills. 1984;58(3):719-725.

14. Miller RB. Perceived Instrumentality and Academics: The Link to Task Valuing - Statistical Data Included. J Instr Psychol. 1999:1-9.

15. Kirn A, Benson LC. Engineering Students' Perceptions of Problem Solving and their Future. $J$ Eng Educ.

16. Kirn AN. The Influences of Engineering Student Motivations on Short-Term Tasks and LongTerm Goals. Dissertation. 2014.

17. Markus H, Nurius P. Possible Selves. Am Psychol. 1986;41(9):954-969.

18. Oyserman D, Bybee D, Terry K, Hart-Johnson T. Possible Selves as Roadmaps. J Res Pers. 2004;38(2):130-149. doi:10.1016/S0092-6566(03)00057-6.

19. Major J, Boone H, Tsugawa M, McGough C, Benson L, Kirn A. Engineering Student's Perceptions of the Future: Transferability and Replication of Time Perspective Classifications. In: National Association for Research in Science Teaching 2016 Annual Conference. ; 2016.

20. Kirn A, Benson L. Engineering Students ' Perceptions of the Future : Exploratory Instrument Development. In: 122nd ASEE Annual Conference \& Exposition. ; 2015.

21. Chasmar J, Benson L. Future Time Perspective and Self-Regulated Learning: Multiple Case Studies in Industrial Engineering. In: American Society for Engineering Education. ; 2016.

22. Yoder BL. Engineering by the Numbers. ASEE. 2014:11-47.

23. Fernandez T, Godwin A, Verdín D, et al. More Comprehensive and Inclusive Approaches to Demographic Data Collection. Proc from ASEE 2016 Am Soc Eng Educ Annu Conf Expo. 2016:submitted. doi:10.18260/p.25751.

24. Godwin A. The Development of a Measure of Engineering Identity. 123rd Am Soc Eng Educ Annu Conf Expo. 2016:15.

25. Curran P, West S, Finch J. The Robustness of Test Statistics to Nonnormality and Specificiation Error in Confirmatory Factor Analysis. Phsycological Methods. 1996;1(1):16-29.

26. Cho E, Kim S. Cronbach's Coefficient Alpha: Well Known but Poorly Understood. Organ Res Methods. 2015;18(2):207-230. doi:10.1177/1094428114555994.

27. Fraley C, Raftery a E. How Many Clusters? Which Clustering Method? Answers Via ModelBased Cluster Analysis. Comput J. 1998;41(8):578-588. doi:10.1093/comjn1/41.8.578.

28. Flynn PJ. Data Clustering: A Review. 2000;31(3).

29. Burtner J. The Use of Discriminant Analysis to Investigate the Influence of Non-Cognitive Factors on Engineering School Persistence. J Eng Educ. 2005;94:335-338. doi:10.1002/j.21689830.2005.tb00858.x.

30. Husman J, Lens W. The Role of the Future in Student Motivation. Educ Psychol. 1999;34(2):3741. doi:10.1207/s15326985ep3402. 
Appendix: Example Summary of Results for Instructors

\section{Engineering Undergraduate's Motivations for Being in Engineering: Future Career Perceptions}

A Report of Results by [Authors Redacted] to [Instructor] on

[Course Number], Introduction to Microprocessors

This report presents results from the survey distributed in [Instructor]'s [Course Number] class. The results from this class will be included in the data for the larger study described in the Project Summary.

\section{Overview of Results}

The results from the survey show that one third (33\%) of the students in [Course Number] have a specific future career in engineering that they are working towards; this group of students are finding the information they are learning [Course Number] to be useful for their future. About one third (35\%) of students have a future goal in engineering, but do not believe they will be able to achieve it; nonetheless, this group finds their grade in [Course Number] to be important to reaching that goal. And about one third (32\%) do not have a specific future career goal, and are in engineering because of the breadth of jobs it will prepare them for. These students do not find the class material or their class grade in [Course Number] particularly useful for their future.

\section{Project Summary}

The purpose of this study is to identify a population of undergraduate engineering students in large enrollment classes with a different distribution of characteristic future time perspectives (FTPs) than the norm within their major, describe how this population of students approaches ill-structured problems, and explain how this population of students' FTP relate to how they approach ill-structured problems. I seek to answer the research question, "How does the problem solving approaches of undergraduate engineering students in large enrollment classes with different perceptions of the future than the norm within their major relate to their different perceptions of the future?" This can inform instructors of large enrollment classes how to encourage students with different ways of thinking to persist in engineering.

I will quantitatively identify a group of students with different ways of perceiving the future, and qualitatively explore how they perceive the future. The ways students perceive the future will be based on previously determined characteristic types of Future Time Perspectives (FTP). FTP is the personal and individual way of thinking about the future-the future goals and how those goals affect their future.

Understanding how FTPs affect problem solving skills of students will help instructors know where to focus their attention when teaching students to solve ill-structured problems such as those they will encounter after graduation. I will share the results of this study so engineering instructors can use the FTP survey to understand their students' FTPs and adjust their instruction appropriately. This will be particularly valuable in large enrollment engineering programs where class sizes are large and professors may not have opportunities to gain insight into their students' motivations and goals.

Survey Measured Seven Constructs that Together Describe Students' Beliefs about the Future 
Table 1 contains a list of constructs on the survey and what a high score on that construct indicates ${ }^{6,7,31}$ :

\begin{tabular}{|c|l|l|}
\hline \multicolumn{3}{|c|}{ Table 1: Constructs of The Students' Future Goals Measured on the Survey } \\
\hline $\mathbf{1}$ & Clarity of Future Goals & The student has a well-defined future goal, deep into the future. \\
\hline $\mathbf{2}$ & Value of the Future & $\begin{array}{l}\text { The student believes that setting goals deep into the future is } \\
\text { valuable. }\end{array}$ \\
\hline $\mathbf{3}$ & $\begin{array}{l}\text { Perceptions of the Future in } \\
\text { Engineering }\end{array}$ & The student is certain about being an engineer. \\
\hline $\mathbf{4}$ & $\begin{array}{l}\text { Effect of the Future on the } \\
\text { Present }\end{array}$ & $\begin{array}{l}\text { The student recognizes that their future goals affect what they } \\
\text { do in the present. }\end{array}$ \\
\hline $\mathbf{5}$ & $\begin{array}{l}\text { Exogenous Perceived } \\
\text { Instrumentality }\end{array}$ & $\begin{array}{l}\text { The student finds their class grade to be useful for their future } \\
\text { career. }\end{array}$ \\
\hline $\mathbf{6}$ & $\begin{array}{l}\text { Endogenous Perceived } \\
\text { Instrumentality }\end{array}$ & The student finds their class useful for their future career. \\
\hline $\mathbf{7}$ & $\begin{array}{l}\text { Time Attitude towards the } \\
\text { Future }\end{array}$ & The student has a positive view about their future possibilities. \\
\hline
\end{tabular}

\section{$\underline{\text { Resulting Groups are Consistent with Previous Research }}$}

A k-means cluster analysis was implemented with data collected from three institutions $(\mathrm{N}=416)$ to identify groups of students with similar beliefs about the future. K-means cluster analysis is appropriate for large sample sizes where the number of clusters $(k=3)$ is hypothesized based on theory or previous studies $^{28,32,33}$. The cluster analysis resulted in three groups with means consistent with previous research $^{7,20,34}$. To visualize these groups, a cone analogy is used (Figure 1).
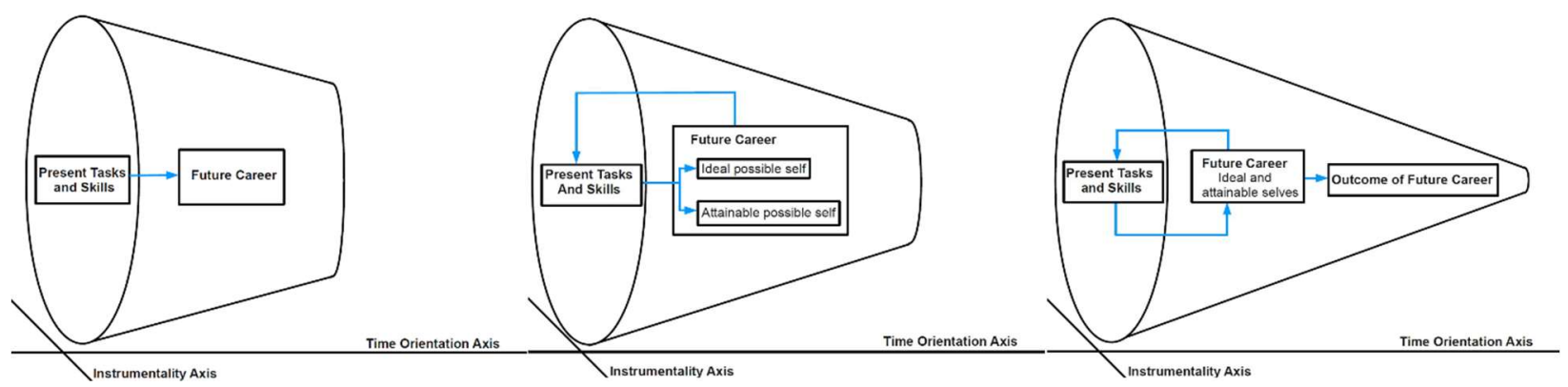

Figure 1: Cake (left) has a shorter and wider cone, representative of their shorter extension into the future; Sugar (right) has high clarity (one goal deep into the future), represented by the long pointy cone shape; and Waffle (middle) has a medium cone width and depth compared to the Cake and Sugar ${ }^{16}$.

What These Groups Look Like in [Course Number]

Based on the results from the survey and descriptions from previous research ${ }^{9,19,34}$, the different groups in [Course Number] are shown in Table 2 and described on the next page:

Sugar: One third of the class (33\%) has well-defined future goals. These students know what they want to be up to 10 years in the future (clarity of future goals) in engineering (perception of future in engineering). These students believe they can achieve their goal (future time attitude), and are 
motivated to work in your class because of their future goals (perceived instrumentality and effect of future on present). Their high endogenous perceived instrumentality means that you are effectively connecting what they are learning in the class to their future goals. The lower exogenous perceived instrumentality indicates that they are not as motivated by their grades.

Waffle: Slightly over one third of the class (35\%) has a more negative outlook of the future (future time attitude). These students have a moderately well-defined goal after graduation (clarity of future goals), but they do not think they will be able to achieve this goal, most likely due to not having high enough grades, which is making the grade in this class important for their future goals (Exogenous Perceived Instrumentality). The low endogenous and high exogenous perceived instrumentality indicate that these students are not as focused on the content as they are with grade they will receive.

Cake: $32 \%$ of the students in the class have a more broad conception of the future, and are not thinking past their first job after graduation (clarity of future goals). They are most likely in engineering because of the wide range of future careers it allows (future in engineering); in other words, all things are still possible (future time attitude). Typically these students have a high endogenous perceived instrumentality; because of these wide range of possible goals, any information they learn could be relevant to their future. But in this class, the students in the Sugar are finding the information in the class more relevant to their future.

\begin{tabular}{|l|c|c|c|}
\hline \multicolumn{3}{|c|}{ Table 2: Construct Means for Each Group in [Course Number] } \\
\hline & Cake & Sugar & Waffle \\
\hline Percent of Sample & $32 \%$ & $33 \%$ & $35 \%$ \\
\hline Clarity of Future Goals & $\downarrow$ & $\uparrow$ & - \\
\hline Value of the Future & $\downarrow$ & $\uparrow$ & - \\
\hline Perception of Future in Engineering & $\downarrow$ & $\uparrow$ & - \\
\hline Effect of the Future on the Present & $\downarrow$ & - & $\uparrow$ \\
\hline Exogenous Perceived Instrumentality & - & - & $\uparrow$ \\
\hline Endogenous Perceived Instrumentality & - & $\uparrow$ & $\downarrow$ \\
\hline Time Attitude of the Future & - & $\uparrow$ & $\downarrow$ \\
\hline
\end{tabular}

Note: $\uparrow$ indicates the group with the highest score on a construct, $\downarrow$ the lowest score on a construct, and - the medium score.

\section{Implications for Instruction in [Course Number]}

The end of the semester is approaching soon, and tasks in your class are likely getting more difficult. Students' beliefs are increasingly important for their success on difficult tasks. The belief that difficult tasks are important as well as the belief that the future is valuable is correlated to higher academic achievement and persistence ${ }^{35,36}$. The students who are motivated by their future goals (Sugar) are finding the course material important for their future, and believe that the future is valuable. For those students who are more focused on the present (Cake and Waffle), you need to connect the future to the 
"now" to motivate the students to learn and understand the material (endogenous perceived instrumentality).

There are many ways to help connect your students' future to their present by adjusting the language you use in your classroom. Talking about the future as a path, and speaking of the future as "near" rather than "far" can help students see the value of the future by connecting it to the present. Also, using smaller time units (days vs. years) makes the future seem more connected to the right now ${ }^{37}$ (i.e. "You will use this in your classes sophomore year, in 121 days." Or "You may see this in your first job after graduation, which is in 1095 days.").

\section{Sample is Representative of National Averages}

The students who consented to participate in the survey in [Course Number] $(N=54)$ are included in this analysis (Table 3). The sample is representative of the national undergraduate engineering population according to race, gender, and residency as shown in Table 4.

\begin{tabular}{|c|c|c|c|}
\hline \multicolumn{4}{|c|}{ Table 3: Sample Size } \\
\hline $\begin{array}{c}\text { Students in } \\
\text { [Course Number] }\end{array}$ & $\begin{array}{c}\text { Students who } \\
\text { Responded }\end{array}$ & $\begin{array}{c}\text { Students who Consented } \\
\text { to Participate }\end{array}$ & $\begin{array}{c}\text { Response } \\
\text { Rate }\end{array}$ \\
\hline 58 & 54 & 54 & $93 \%$ \\
\hline
\end{tabular}

\begin{tabular}{|l|c|c|c|c|}
\hline \multicolumn{5}{|c|}{ Table 4: Demographics for [Course Number] and Nationally } \\
\hline & White & Male & Heterosexual & Born in US \\
\hline [Course Number] & $78 \%$ & $74 \%$ & $98 \%$ & $91 \%$ \\
\hline $\begin{array}{l}\text { National Undergraduate } \\
\text { Engineering Population }\end{array}$ & $64 \%$ & $81 \%$ & NA & $91 \%$ \\
\hline
\end{tabular}

Note: To determine that the survey is reliable for this sample, a maximum likelihood factor analysis using promax rotation was used ${ }^{6,7,31,34,38-42}$. Cronbach's alphas for all of the constructs were sufficiently high $(>.6)^{43}$.

\section{Future Work}

This information is intended to inform you of the different ways students in your class are thinking about their future careers in engineering. I encourage you to use this information to appeal to your students' attitudes and beliefs through your instruction. Future work for this study will include results on how these different groups are approaching problems. I will continue to update you with results from this study. Until then, please feel free to contact me with any questions.

[Signature]

\section{$\underline{\text { References }}$}

1. Cresswell JW, Clark VLP. Designing and Conducting Mixed Methods Research. second. Sage publications; 2011.

2. National Academy of Engineering. Grand Challenges for Engineering. http://www.engineeringchallenges.org/. Published 2012.

3. National Academy of Engineering. Advance Personalized Learning. NAE Grand Challenges for Engineering. 
4. Malka A, Covington M V. Perceiving school performance as instrumental to future goal attainment: Effects on graded performance. Contemp Educ Psychol. 2005;30(1):60-80. doi:10.1016/j.cedpsych.2004.04.001.

5. Lens W, Paixão MP, Herrera D, Grobler A. Future time perspective as a motivational variable: Content and extension of future goals affect the quantity and quality of motivation. Jpn Psychol Res. 2012;54(3):321-333. doi:10.1111/j.1468-5884.2012.00520.x.

6. Husman J, Lens W. The Role of the Future in Student Motivation. Educ Psychol. 1999;34(July 2014):113-125. doi:10.1207/s15326985ep3402.

7. McGough C, Kirn A, Benson L. Work in Progress : Developing a Quantitative Instrument for Measuring Undergraduate Engineering Students ' Future Time Perspectives. In: American Society for Engineering Education. ; 2016.

8. Hilpert J, Husman J, Stump GS, Kim W, Chung WT, Duggan MA. Examining students' future time perspective: Pathways to knowledge building. Jpn Psychol Res. 2012;54(3):229-240. doi:10.1111/j.1468-5884.2012.00525.x.

9. McGough C, Kirn A, Benson L. Relationships between Engineering Students' Future Time Perspectives and Their Problem Solving Processes. NARST Conf. 2015:1-5.

10. McGough C, Faber C, Kirn A, Benson L. Connections between Undergraduate Engineering Students' Problem Solving Strategies and Perceptions of Engineering Problems. In: ASEE Annual Conference. ; 2015.

11. Husman J, Shell DF. Beliefs and perceptions about the future: A measurement of future time perspective. Learn Individ Differ. 2008;18(2):166-175. doi:10.1016/j.lindif.2007.08.001.

12. Husman J, Derryberry WP, Crowson HM, Lomax R. Instrumentality, task value, and intrinsic motivation: Making sense of their independent interdependence. Contemp Educ Psychol. 2004;29:63-76. doi:10.1016/S0361-476X(03)00019-5.

13. Daltry MH, Langer P. Development and Evaluation of a Measure of Future Time Perspective. Percept Mot Skills. 1984;58(3):719-725.

14. Miller RB. Perceived Instrumentality and Academics: The Link to Task Valuing - Statistical Data Included. J Instr Psychol. 1999:1-9.

15. Kirn A, Benson LC. Engineering Students' Perceptions of Problem Solving and their Future. J Eng Educ.

16. Kirn AN. The Influences of Engineering Student Motivations on Short-Term Tasks and Long-Term Goals. Dissertation. 2014.

17. Markus H, Nurius P. Possible Selves. Am Psychol. 1986;41(9):954-969.

18. Oyserman D, Bybee D, Terry K, Hart-Johnson T. Possible Selves as Roadmaps. J Res Pers. 2004;38(2):130-149. doi:10.1016/S0092-6566(03)00057-6.

19. Major J, Boone H, Tsugawa M, McGough C, Benson L, Kirn A. Engineering Student's Perceptions of the Future: Transferability and Replication of Time Perspective Classifications. In: National Association for Research in Science Teaching 2016 Annual Conference. ; 2016.

20. Kirn A, Benson L. Engineering Students' Perceptions of the Future : Exploratory Instrument Development. In: 122nd ASEE Annual Conference \& Exposition. ; 2015.

21. Chasmar J, Benson L. Future Time Perspective and Self-Regulated Learning: Multiple Case Studies in Industrial Engineering. In: American Society for Engineering Education. ; 2016.

22. Yoder BL. Engineering by the Numbers. ASEE. 2014:11-47.

23. Fernandez T, Godwin A, Verdín D, et al. More Comprehensive and Inclusive Approaches to Demographic Data Collection. Proc from ASEE 2016 Am Soc Eng Educ Annu Conf Expo. 2016:submitted. doi:10.18260/p.25751.

24. Godwin A. The Development of a Measure of Engineering Identity. 123rd Am Soc Eng Educ Annu Conf Expo. 2016:15. 
25. Curran P, West S, Finch J. The Robustness of Test Statistics to Nonnormality and Specificiation Error in Confirmatory Factor Analysis. Phsycological Methods. 1996;1(1):16-29.

26. Cho E, Kim S. Cronbach's Coefficient Alpha: Well Known but Poorly Understood. Organ Res Methods. 2015;18(2):207-230. doi:10.1177/1094428114555994.

27. Fraley C, Raftery a E. How Many Clusters? Which Clustering Method? Answers Via Model-Based Cluster Analysis. Comput J. 1998;41(8):578-588. doi:10.1093/comjnl/41.8.578.

28. Flynn PJ. Data Clustering : A Review. 2000;31(3).

29. Burtner J. The Use of Discriminant Analysis to Investigate the Influence of Non-Cognitive Factors on Engineering School Persistence. J Eng Educ. 2005;94:335-338. doi:10.1002/j.21689830.2005.tb00858.x.

30. Husman J, Lens W. The Role of the Future in Student Motivation. Educ Psychol. 1999;34(2):37-41. doi:10.1207/s15326985ep3402.

31. Husman J, Lynch C, Hilpert J. Validating Measures of Future Time Perspective for Engineering Students: Steps Toward Improving. 2007.

32. Kaufman L, Rousseeuw PJ. Finding Groups in Data. Printed in the United States of America: A Wiley-Intersecience Publication; 1990.

33. Fraley C, Raftery E. How Many Clusters? Which Clustering Method? Answers Via Model-Based Cluster Analysistle. Comput J. 1998;41(8):578-588.

34. Kirn A, Faber C, Benson L. Engineering Students Perception of the Future: Implications for Student Performance. Am Soc Eng Educ. 2014.

35. Oyserman D. YouTube: IAS Distinguished Lecture Daphna Oyserman. :Online Video Clip.

36. Nelson KG, Shell DF, Husman J, Fishman EJ, Soh LK. Motivational and self-regulated learning profiles of students taking a foundational engineering course. J Eng Educ. 2015;104(1):74-100. doi:10.1002/jee.20066.

37. Lewis NA, Oyserman D. When Does the Future Begin? Time Metrics Matter, Connecting Present and Future Selves. Psychol Sci. 2015:956797615572231. doi:10.1177/0956797615572231.

38. Benson L, Kirn A, Mcgough C, Faber C. CAREER : Students ' Perceptions of Problem Solving Driven by Motivations Across Time Scales. Am Soc Eng Educ. 2015.

39. Fabrigar LR, Wegener DT, MacCallum RC, Strahan EJ. Evaluating the use of exploratory factor analysis in psychological research. Psychol Methods. 1999;4(3):272-299. doi:10.1037/1082989X.4.3.272.

40. Osborne JW. What is Rotating in Exploratory Factor Analysis? Pract Assessment, Res Eval. 2015;20(2):1-7. doi:10.1037/e558952014-001.

41. Costello AB, Osborne JW. Best Practices in Exploratory Factor Analysis: Four Recommendations for Getting the Most From Your Analysis. Pract Assessment, Res Eval. 10(7):27-29. doi:10.1.1.110.9154.

42. Curran PJ, West SG, Finch JF. The robustness of test statistics to nonnormality and specification error in confirmatory factor analysis. Psychol Methods. 1996;1(1):16-29. doi:10.1037/1082989X.1.1.16.

43. DeVellis RF. Scale Development: Theory and Applications. Sage publications; 2012. 